\title{
Using ACCounTABILITY Logs To AsSESS INDIVIDUAL STUDENT ConTributions to CAPSTONE PRoJects: WHAT HAPPENS WHEN ONE STUDENT ON A TEAM FAILS?
}

\author{
Carolyn G. MacGregor ${ }^{1}$, Stacey Scott ${ }^{2}$, and Matthew J. Borland ${ }^{1}$ \\ ${ }^{1}$ University of Waterloo, ${ }^{2}$ University of Guelph \\ Corresponding author email: carolyn.macgregor@uwaterloo.ca
}

\begin{abstract}
To discourage social loafing, the need for fair differential grading among team members led to the development and use of Accountability Logs(ALs) and associated evidence-based rubrics as tools to help Capstone Coordinators identify individual students failing to make meaningful and competent technical contributions. While traditional Engineering logbooks tend to be hard-covered notebooks documenting the design analysis, sketches, calculations, and results of a project, ALs can be in electronic format to allow for importing of multi-media examples of works in-progress or completed. ALs must contain a) Evidence - explicit accounting of the student's independent technical contributions to the project on a minimum weekly basis; b) Learning - reflection on value added from personal contributions to the overall project goals; and $c$ ) Planning - articulation of logical next steps for moving forward with technical contributions to meet project goals. The $A L$ components align with the Graduate Attribute of Life-Long Learning. Through experience with three cohorts of students (Fall 2014 - Winter 2017), we explain the evolving use of ALs; how ALs are currently situated in the overall assessment of the student team members of Capstone Engineering Projects; and our current recovery options for students who receive failing grades in the Capstone course.
\end{abstract}

Keywords: Capstone Projects, Accountability Logs, Social Loafing, Student Failure/Recovery, Life-Long Learning.

\section{INTRODUCTION}

As part of Canadian Engineering Accreditation Board (CEAB) process in 2013-2014, the Department of Systems Design Engineering (SYDE) at the University of Waterloo had opportunity to review closely the deliverables associated with its 2-term Capstone course suite (SYDE 461-462) which is held in the Fall and Winter terms preceding graduation. An on-going expectation is that all SYDE Capstone projects include rigorous needs assessment, design, analysis, and validation activities, applying different engineering design methodologies as appropriate in each phase and iteration throughout the two-term project. All projects must produce a demonstrable, testable engineering design outcome, rather than simply theoretical outcomes. Prior to Fall 2014, a typical SYDE Capstone project team consisted of 2-6 students; and an individual student's Capstone course grade was determined by team submissions with the primary deliverables being a project proposal at the start of the project, a series of design reviews across the two terms, a public presentation and demonstration of the designed functional prototype, team peer assessments, and a final technical report which included a summary of individual team member contributions. With cohorts of 70-90 students, individual contributions were not scrutinized by the Capstone Coordinator or Project Supervisor unless a complaint was specifically lodged.

When teams are working positively together, they can motivate one another to tackle complex problems, help each other develop skills and share learning. On the downside, without an emphasis on accountability students can fall into patterns of social loafing [7]. Typically, individual students are rarely given a grade substantially different from that awarded to the team.

Even though all SYDE Capstone teams created team contracts and worked with faculty members as advisors, disputes over adequate technical contribution to a team project often came down to student claims at term's end when opportunity to document personal contributions had been lost or neglected. Both students and faculty advisors were finding the assessment process lacking when it came to holding individual students accountable. Faculty raised concerns that weaker students seemed to be relying heavily on "plug-and-play" components for their system designs rather than careful analysis and design. We also received candid feedback from alumni who, as employers and senior managers, better appreciated the folly of 
ignoring or facilitating the social loafing or technical incompetence of one or more team members. Such feedback, along with our own observations, provided impetus for substantial change in our Capstone Project assessment process.

To assess and apply differential grading fairly among team members, we needed an approach that was evidencebased rather than relying on personal arguments. For this reason, in Fall 2014 two major components were added to our SYDE Capstone Project assessment process: a) the reintroduction of team panel examinations at the end of the Fall and Winter terms; and b) the inclusion of individual student Accountability Logs requiring each student to personally account for their commitment to the project, and to provide evidence of meaningful and competent technical contributions; where, meaningful refers to logical and necessary, and competent technical contributions refers to level-appropriate engineering analysis, design, prototyping, testing, and validation. The use of a panel examination format as an assessment tool is not particularly novel, so we will only describe the panel examination occurrences in relation to the failure/recovery process for individual students. To the best of our knowledge, the use of individual Accountability Logs and the associated assessment rubrics we have developed constitutes a novel approach to assessing the contributions of individual students on Capstone project teams. Having used this approach now with three cohorts of SYDE students, we share our learning as Capstone Coordinators with the intention of sparking conversations to further develop fair assessments of individuals within team-based project situations.

\section{ACCOUNTABILITY LOGS}

Prior to our AL initiative, student contributions were typically captured in a summary table embedded in the team's final report. With team membership ranging from 2-6 students, it was easy for some students on larger teams to contribute little and still pass the Capstone courses. For the 2014-2015 cohort, team membership was restricted to 4-5 students to make for more equitable workload and expectations across teams. Further, all team members were explicitly required to contribute in a meaningful and competent way to the technical aspects of the project. On top of this, all students were expected to participate in the general project management and technical writing of team deliverables. These requirements removed the "team risk management strategy" of forced social loafing. Forced social loafing, as we define it, occurs when some students are relegated by other team members to tasks, such as meeting coordination or report writing, and essentially denied the opportunity to develop their technical skills or contribute to the engineering aspects in a substantial way. Often this strategy is used when students who perceive themselves to be technically stronger try to manage risk of poor grades by curbing technical input from others. We tried to empower all students by making meaningful and competent technical contributions mandatory.

Since conflicts in team member schedules can be an inhibitor to project success [1], we reminded students that each team needed to coordinate 1 hour per week for full team meetings, with each individual student committing a minimum of 7-10 hours per week devoted to their own technical contributions to the project. Each student was to maintain a personal Accountability Log which would be graded, and used for flagging students who were not adequately contributing to the Capstone project.

We purposely used the term Individual Accountability Logs to reinforce that students would be held accountable for their own work, and to differentiate from traditional Engineering Notebooks used in earlier design courses in the curriculum which often defaulted to a collection of team meeting minutes. Students were also made aware that final team presentations for each term would be done as Panel Examinations with 4-person technical panels consisting of Captstone Coordinator(s) and subject matter experts. Individual students would be asked questions directly about their technical contributions.

To be accountable, one must be able to rationally assess one's work own work by reviewing quality and progress against relevant standards, reflect on personal growth through the experience, and identify knowledge, skills, and tools for further action. Being accountable aligns with the Canadian Engineering Accreditation Board (CEAB) Graduate Attribute Life-Long Learning [3]. Therefore, all Accountability Logs required: a) Evidence explicit accounting of the student's independent technical contributions to the project on a weekly basis; b) Learning - reflection on value added from personal contributions to the overall project goals; and c) Planning - articulation of logical next steps for moving forward with technical contributions to meet project goals. Table 1 presents the basic directions for the three main AL components.

Table 1: Accountability Log Component Instructions

A. Evidence: Describe and/or illustrate individual contributions to the team design project;

- What did you do? How do we know you did it? (Proof may be in terms of handwritten entries; annotated illustrations or pictures; select communications; etc.)

B. Learning: Comment on personal learning from design project task outcomes;

- What did you learn? (could be interpretation of results; could be better understanding of skill or resource limitations; could be realization that project is not headed in productive direction - be honest)

C. Planning: Identify and track personal management of assigned project tasks;

- What were you assigned to do, or take the initiative to do? Did you complete it? If no, why not (be honest). What do you need to do next? 
The format and layout of the AL was at the discretion of the individual student. Hard-copy bound notebooks, electronic document compilations, or combinations were acceptable. An advantage of electronic formats was that it was easier for students to leverage photos or videos of work in progress, sketches and visualizations to use as evidence of work done or in progress. Electronic documents also made assessment easier for faculty in that written notes were more likely to be typed. Further, electronic documents uploaded to the University of Waterloo's Learning Management System "LEARN" (D2L), could be reviewed by multiple evaluators when second opinions were needed.

During Iteration-1 (Fall 2014 - Winter 2015), 25\% of the 71-student cohort made electronic AL submissions, with the other $75 \%$ using more traditional Engineering notebooks. During Iteration-2 (Fall 2015-Winter 2016), almost $90 \%$ of the 81 -student cohort created electronic ALs. For the most recent Iteration-3 (Fall 2016 - Winter 2017), $100 \%$ of the 67 -student cohort submitted all or some portion of their ALs in electronic format.

\section{ASSESSING ACCOUNTABILITY}

During Iteration-1, AL assessment results were used for differential grading of team members, but not for failing a student in the course. We were upfront with the students that we were experimenting with a new approach to capture individual student accountability. Most students seemed to understand and appreciate the need for assessing accountability, as many had experienced some form of team dysfunction as part of an earlier course, or while on a co-op work term. The main concerns raised by students were around what to log; how much to log; and whether their time would be better spent working on their project rather than documenting progress. Our sense was that logging was only a time problem for those who were truly invested in their design projects resulting in many details to report. Interestingly, these students were also the ones more likely to see value in formally capturing their design process to help with justifying design decisions in technical reports, and for forming the basis of their design portfolios to show to potential employers.

Since we wanted students to report honestly, we agreed with the Iteration-1 class that an individual student or team would not fail the course based on their ALs. In other words, independent grading of students occurred only for the AL component, and all team members would receive the same grade for team deliverables. During the first term of Iteration-1, AL submissions were worth a total of $20 \%$ of the student's Capstone course grade (5\% Interim evaluation; 15\% End-of-Term); and boosted to $25 \%$ in the second term of Iteration-1 (10\% Interim; $15 \%$ Term, which included an Individual Student Project Post-
Mortem). Similar grade weightings were used in Iteration2. Based on feedback from students and faculty, Iteration3 saw a realigning of the $25 \%$ for individual student grade components to better balance AL reporting (5\% Interim; $10 \%$ End-of-Term) with individual performance in the Panel Examination (10\%) which had not been specifically included in Iteration-1 or Iteration-2.

\subsection{Grading Accountability Logs}

As a first pass at grading, a qualitative rubric was designed that made use of a 5-point scale reflecting the three major $\mathrm{AL}$ components as well as submission organization. For illustration, a partial example of the rubric is provided in Table 2. As these were senior undergraduate students, phrasing of submission quality relating to reference letters for graduate schools or permanent employment seemed meaningful to them. Given that our SYDE curriculum has design courses starting in 1A (first term of first year), categorization of quality and depth of insight reflected expectations for students to go beyond elementary design skills. Future versions of the grading rubrics retained this general approach, with later versions providing specific subrubrics for each of the three AL components.

Table 2: General rubric for Accountability Logs (partial)

\begin{tabular}{|c|c|}
\hline Level (Score) & Description \\
\hline $\begin{array}{l}\text { Level } 5 \text { - } \\
\text { Professional } \\
\text { Engineering / } \\
\text { Graduate } \\
\text { Level }(5 / 5)\end{array}$ & $\begin{array}{l}\text { A) Documentation/evidence of student's } \\
\text { contributions is impressive for a } 4^{\text {th }} \text { year } \\
\text { student. } \\
\text { B) Insights into problem area \& learning worthy } \\
\text { of a top } 10 \% \text { reference for employment/grad } \\
\text { school. } \\
\text { C)Project contribution is substantial. } \\
\text { D) Organization of submission facilitates } \\
\text { evaluation of project evolution and student's } \\
\text { contributions. }\end{array}$ \\
\hline $\begin{array}{l}\text { Level } 3 \text { - } \\
\text { Working at a } \\
\text { 3rd year level } \\
(3 / 5)\end{array}$ & $\begin{array}{l}\text { A) Documentation/evidence of contributions } \\
\text { much less than expected of a 4th year } \\
\text { student } \\
\text { B) Insights are very general or reflect } \\
\text { misunderstandings of design or engineering } \\
\text { analysis. Work presented unworthy of a } \\
\text { reference for employment/grad school. } \\
\text { C) Project contribution appears sufficient. } \\
\text { D) Organization of submission makes it difficult } \\
\text { to follow the project evolution and student's } \\
\text { contributions. }\end{array}$ \\
\hline $\begin{array}{l}\text { Level } 1- \\
\text { Working at or } \\
\text { below 1st } \\
\text { year level } \\
(1 / 5)\end{array}$ & $\begin{array}{l}\text { A) Documentation/evidence contributions is } \\
\text { substantially less than expected. } \\
\text { B) Insights into problem area and learning are } \\
\text { missing or reflect misunderstandings of } \\
\text { design or engineering analysis fundamentals } \\
\text { taught in lower level courses. } \\
\text { C) Project contribution is unsatisfactory } \\
\text { D) Submission would not pass 1st year level. }\end{array}$ \\
\hline
\end{tabular}


During the Fall term of Iteration-1, one of the authors carried out all AL grading - partly because we didn't know what to expect as previous experience had been with Team Engineering logbooks as referents, and partly to ensure a consistent approach for evaluating the initial submissions. ALs for members of the same team were reviewed at the same time to facilitate cross-checking between group members, and to make note of individuals who seemed to be falling well behind their teammates. AL submissions ranged in length from a few pages to more than 80 pages, making a page-by-page review by one evaluator unsustainable.

In the second term, two evaluators shared the grading duties. Three similar rubrics were created for the main AL components of Evidence, Learning, and Planning using the general rubric as a guide. Exemplars of strong and poor ALs for each category were used to help with grading calibration across evaluators. For Iterations -1 and -2 , students were given a score out of 15 , and feedback on each AL component. For Iteration-3, each student submitted an Interim and End-of term AL Reflection Report (approximately 2 pages) along with their ALs to provide evidence of personal technical contribution. The AL Reports became the primary graded deliverable, with the ALs containing evidence. This allowed the evaluators to focus grading attention on student learning (graded out of 10), and to provide a Pass/Fail assessment of the AL entries as a composite. Table 3 provides the AL Reflection questions; and, Table 4 presents a portion of the grading rubric for assessment context.

Table 3: AL Reflection Report Questions The End of Term Reflection component must directly answer the following questions:

1.What were your personal contributions to the project? 2. How did your individual work affect design decisions and the final outcomes of the project?

3.What were the most important things you learned in terms of the technical skills required to complete your project? How did you learn these things?

4. How well did your team function with regards to project management and teamwork?

5.How did you overcome obstacles?

6. How has this project affected your outlook on design and the iterative design process?

Table 4: AL Reflection Report Grading Rubric (partial)

\begin{tabular}{|l|l|}
\hline $\begin{array}{l}\text { Outstanding } \\
9-10\end{array}$ & $\begin{array}{l}\text { All questions are answered and student } \\
\text { learning is obvious. Insight is communicated } \\
\text { in a clear, concise manner which strongly } \\
\text { conveys the experiences which have led to } \\
\text { personal growth. }\end{array}$ \\
\hline $\begin{array}{l}\text { Satisfactory } \\
6-7\end{array}$ & $\begin{array}{l}\text { All questions are answered and student } \\
\text { learning can be interpreted from the } \\
\text { responses. Discussion could use more depth } \\
\text { and insight. }\end{array}$ \\
\hline $\begin{array}{l}\text { Unsatisfactory } \\
0-5\end{array}$ & $\begin{array}{l}\text { Some questions are not answered, or } \\
\text { answers are too brief or vague to assess if } \\
\text { any real learning has occurred. }\end{array}$ \\
\hline
\end{tabular}

\subsection{Student Results}

As mentioned, initial implementation of ALs resulted in no individual failures in the Capstone course; however, 3 students received AL scores below 60\%. It is worth noting that promotion rules in the Faculty of Engineering at the University of Waterloo are such that a passing grade for a course is $50 \%$, while a grade point average of $60 \%$ is needed to pass the academic term. While there may have been some initial posturing of "entitlementality" [4], most students who were performing poorly at the interim assessments admitted that they were not spending the expected 7-10 hours per week on their Capstone projects because other activities were taking priority, such as interviews for permanent jobs post-graduation.

For Iterations 2-3, it was communicated in the course syllabi that in addition to the individual components, the instructor reserved the right to assign individual students a fraction of the total group mark on any specific teambased deliverable without sufficient evidence of that student's contribution to the group effort. The onus was on each individual student to provide evidence of their individual contribution to the team effort. We also clearly stated that the Capstone Coordinators reserved the right to compare entries across team members, speak directly with the team, and/or consult the named supervisor for clarification of entries before finalizing grades. Figure 1 shows Accountability Logs as providing a base for the student's own evidence along with answering of questions at panel exams, and contributing to meetings with the Project Supervisor and Course Coordinator, with the individuals input being weighed against evidence from team examination, deliverables, and inputs from others.

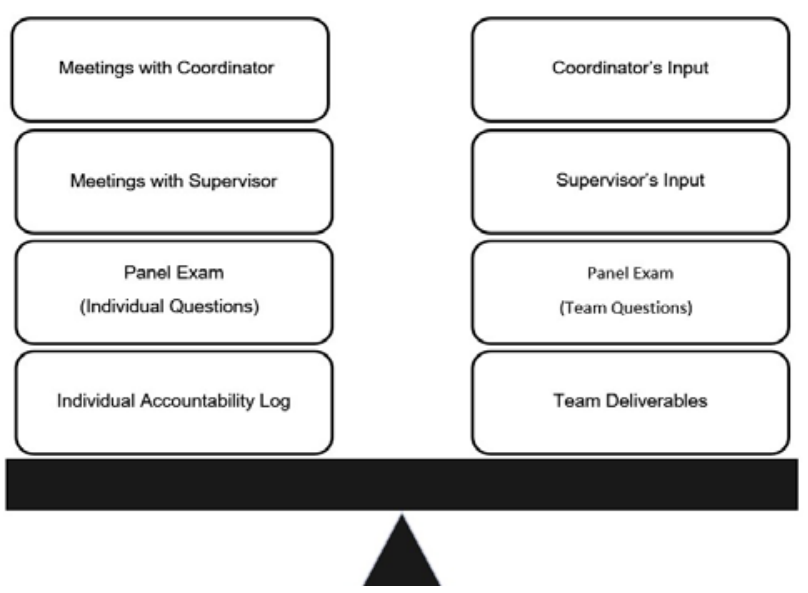

Fig. 1. Balancing Inputs to Student Assessment

Despite feedback on ALs, and repeated meetings with and warnings by Course Conductors, marginal and failing course grades were assigned to some students. 
To put Capstone failure rates and marginal course grades into perspective, we reviewed the SYDE Capstone course grades posted for 1997 to 2017. Only four students had received a Capstone grade or standing lower than $60 \%$ in 19 years (1997-2015 inclusive of Iteration-1). In contrast, during Iteration-2 (grades posted in 2016), six students received Capstone course grades between 50-59, and two students were assigned failing course grades $(<50 \%)$. For Iteration-3 (2017), one student was failed outright, and two students were given a supplemental exam prior to the term grades being finalized - with one of these students further failing to demonstrate sufficient competence.

While there may be some generational effects, we attribute the difference in current Capstone course failure rates and pre-AL rates to the revised assessment process which allows for differential grading in the absence of meaningful and competent technical contribution. Prior to 2016, SYDE did not have a mechanism for failing individual students in an evidence-based manner. That said, as educators we had to plan for learning and recovery opportunities for students in the event of failure.

\section{CAPSTONE FAILURE RECOVERY}

Failing a Capstone course, or any course, in the term prior to graduation means that those students are unable to meet degree requirements in time to graduate with their cohort. For the two students who failed in Iteration-2, the second term course of the Capstone project was the only degree requirement left to complete. The Associate Chair Undergraduate Studies reviewed the cases, and agreed to develop a reasonable opportunity for each student to fairly demonstrate the necessary competencies before the end of the Spring 2016 term, so that each student might meet degree requirements to attend Convocation in Fall 2016 (same year as their cohort).

A plan was put in place for each student to specify, scope, and execute an independent project based on their original Capstone project. The failure recover opportunity consisted of having the student submit an individual project plan which leveraged expansion or redesign of a component of the original Capstone project. Essentially, the students had to demonstrate their ability to competently contribute in a technical manner to the original projects. Restricting the project scope to the original project maximized opportunity to learn and improve from earlier feedback, as well as to minimize opportunity for copying a "maker" project from the internet. Each student had approximately 12 weeks to work independently. They could access Department faculty expertise and resources for support. To ensure that the student had done the work, each student was individually examined by a three-member Examination
Panel using a presentation and question/answer period. The student needed to submit a short technical report prior to the Panel Examination. At the Panel Examination, the student gave a 25-minute oral presentation and demonstration of the functional project outcome, followed by a 25-minute question period. Through this process both students cleared the Capstone course failure.

While both students were disappointed in failing their Capstone course, they agreed that their own lack of competent contributions was evident from their $\mathrm{AL}$ submissions. As predicted by Hilchey, accounting for their own decisions and actions provided deeper learning experiences for the students [4]. Experiencing failure, taking ownership for the failure, and working on an independent project to demonstrate reasonable ability to contribute to a technical project resulted in both students expressing gratitude for a fair learning and assessment opportunity. The happy ending for Iteration-2 was that both students attended the Fall 2016 Convocation with their families.

For Iteration-3, the students who had clearly failed to demonstrate meaningful competent technical contributions were made aware of the pending failure, as well as the 12week recovery option. A new addition in Iteration-3, was a 2-week supplemental recovery opportunity for students who had contributed to a meaningful component of the project, but not in a competent manner. The 2-week period limited this recovery option to students who had a failure pending, demonstrated some but not sufficient technical competence during the term, and who could complete the 2-week recovery option before course grades were finalized. The recovery process was similar: revision of technical contribution (e.g. circuit board design, user interface), submission of a brief technical explanation, and a panel examination with demonstration. Students unable to clear the pending failure in the 2-week recovery option defaulted to the 12-week recovery option.

\section{ACCOUNTING FOR LEARNING}

In 2014, we were looking for a method to better understand and assess individual student contributions to team projects. We wanted the method to be fair and transparent so that any differential grading and potential failures would be defendable. We worked with three student cohorts to get better buy-in to the process by listening to their feedback, sharing their created exemplars, and modifying our approaches to make them more sustainable for students and faculty. Our AL approach is a work in progress.

From a cost-perspective, the production of ALs can be stressful for those students who do not care for documenting or tend to obsess over details. Knowing that their own design activities would be reviewed had some students worried that they would be penalized if all entries 
did not look like polished products. Moving towards a pass-fail approach with the AL entries, and focusing instead on the student's learning should help reduce the time and stress experienced by students and evaluators.

Given the sheer volume of information contained in the ALs, we have not conducted formal content analysis on entries. That said, after countless hours of evaluations, follow-up meetings with students and supervisors, discussions with Engineering Technical staff, and our own reflections on the process we present the highlights of our learning.

Like Hickely [4], we had thought that students who received failing grades so close to graduation would put forward entitlement arguments, in keeping with a myth we often hear: "No one fails a Capstone project". Instead, we found that even failing students expect to be held accountable when they trust that the process will be applied to all students. From a fair assessment persective, the primary advantage of using ALs for individual assessment is that it is the student's own work when considered in the context of other team submissions and outcomes that provides justification for differential grading.

Another surprising advantage of ALs was the window they provide into the individual student's perspective on the project, and what each individual student deemed worth documenting. The AL rubrics provided general guidelines for what we would be trying to assess. In turn, each student had to interpret the activities of evidence gathering, learning, and planning as they related to their own project contributions. The details of their AL entries provided us with a snap-shot of a student's Life-Long Learning skills as demonstrated at the time of the entry. It is possible that a meta-analysis of the AL entries may provide insight into the consistency and fluidity of a student's motivation and sense of learning across an 8month project.

One of our original intentions for the ALs was to help spot and curb social loafing on Capstone teams. The combination of ALs and panel exams exposed social loafing in ways that we hadn't expected, and want to better understand. There were some students who admitted in their ALs that their priorities were elsewhere often as explanation as to why work had not gotten done. In some cases, the student was technically strong enough to muscle out last-minute work to help the team, essentially turning the Capstone project into more of a "Hackathon" than a professionally executed design process. The student's AL grades reflected the lack of effort and commitment.

There were also cases where a combination of collective social loafing on a team along with what appeared to be shared Dunning-Kruger effect (i.e. limited knowledge about a field leads to overestimating one's knowledge and abilities without the capacity to recognize errors due to the overestimation) [6] created the "perfect storm" for a team with the results being a design project disaster - poorly designed and constructed prototypes that couldn't possible work as they lacked logical, practical sense. The work of Caputo and Dunning [2] is a more generalized version of the work by Kruger and Dunning [5]; and, it is very relevant to the ALs and what we noticed with some of the engineering design teams. Caputo and Dunning looked at why people have difficulty assessing their own performance, especially when infrequent, ill-structured problems, or open-ended problems are involved. They point out that for tasks, like design tasks, it is almost impossible to know the set of all possible solutions to the problem. As a result, individuals have a difficult time identifying their errors of omission the problem solutions that they didn't derive [2]. This generalization of the Dunning-Kruger effect is very relevant to Capstone Project teams. From our reviews of ALs and panel examinations, the teams and individuals who were overly confident in a seriously flawed solution, also tended to be the ones who provided little or limited research into the field, and provided limited potential solutions - often jumping directly to a single solution.

To the Capstone Coordinator and the Project Supervisor the lack of appropriate knowledge, skills, and discipline-specific awareness were clear from the ALs and meetings with the teams, and feedback was provided accordingly. In a testament to student honesty and trust, a few students acknowledged in their ALs that they had received disappointing feedback, and then proceeded to add in their entries why they believed themselves or their designs to be competent - knowing that the same Coordinator would be reading their next AL submission.

Through the ALs, we have gained more insight into forced social loafing. For example, we found that some students who were not contributing in a meaningful or competent way to the team project were performing well in other technical courses. Reviewing ALs, speaking with teams and supervisors, and speaking with the students in question, we are aware that forced social loafing may be worse among cohorts who have been together for most of their academic program. With familiar cohorts, students have had numerous opportunity to work in small and larger teams as part of lab-based courses and design courses. Students who have a reputation of providing lower-quality work, or late work, or who lack initiative to start tasks and wait to be directed tend to find that the others on the team relegate tasks that are of low technical impact - or do not assign tasks to the student at all.

Even when students select to work with friends, if the project solution takes on a form that requires specific skills that only one or two on the team have, then some students may find that they are tackling the early research work, literature reviews, and patent searches, but then have little to offer as solution directions were chosen in 
ways that excludes their participation. We are beginning to appreciate that forced social loafing has more complexity due to team dynamics than the delegation or relegation of tasks might suggest. We are using such learning to better inform our requirements relating to team composition, student skill development and inclusive Capstone projects.

We posit that ALs provide clues into how students think about their engineering skills as they near graduation, and may help us to better approach conversations with students who are assessing their competencies quite differently than others may assess them. Mamaril et al [6] encourage engineering educators to better understand the underlying thinking and motivations that students have about their own skills and how such thinking can contribute positively or negatively to academic success. The General Engineering SelfEfficacy Scale and the Engineering Skills Self-Efficacy Scale are two questionnaire-based instruments that have been developed and validated with engineering students [6]. Administration of self-efficacy assessments along with ALs and AL Reports in earlier design courses may help to identify students who risk being social loafers due to over or underestimating their engineering skills. Early identification may help with development of appropriate interventions such as targeted teamwork training, or prototyping skills workshops with the goal to increase student skills, reduce forced social loafing, and ultimately eliminate the need for Capstone failure recovery options.

In summary, Accountability Logs (ALs) and the AL Reflective Reports allow students to convey directly and indirectly through their own words and selected evidence, their motivations, learning, and technical competencies displayed through engagement with their Capstone projects. ALs in combination with panel exams and team deliverables provide a fair way to assess whether an individual student has made a meaningful, technical contribution to the Capstone project. ALs can be used as tools to assess aspects of Life-Long Learning; and, when considered across team members may provide insights into variations of social loafing. We have used ALs in the context of Capstone projects, and expect that with minor modification ALs could be used in other team-based situations.

\section{Acknowledgments}

We are grateful for the assistance of Gordon Savage, Shahid Haider, and Saman Mohammadi who helped evaluate Accountability Logs; and to Maud Gorbet, Eric Kubica, Chris McClellan, and Orion Bruckman who provided feedback on the Capstone Failure Recover options. Most of all, we acknowledge the contributions of our students who were willing to work with us to develop
Accountability assessment tools; and especially to those students who have opted to recover from failure in gracious ways.

\section{References}

[1] LeRoy Alaways, "Factors that inhibit or enable success of capstone design teams.” In Proc. Fall 2010 Mid-Atlantic ASEE Conference, (Villanova University; October 15-16, 2010), 8pp. 2010. Available as of May 15, 2017 from https://www.asee.org/documents/sections/middle-atlantic/fall2010/01-Factors-that-Inhibit-or-Enable-Success-of-CapstoneDesign-Te.pdf

[2] Denna Caputo and David Dunning, "What you don't know: The role played by errors of omission in imperfect selfassessments.” Journal of Experimental Social Psychology, vol. 41, no.5, pp. 488-505, 2005. DOI:http://dx.doi.org/10.1016/j.jesp.2004.09.006

[3] Engineers Canada/Ingénieurs Canada “Accreditation Criteria and Procedures/Normes et procedures d'agrément.” 2016. Available as of May 15, 017 from https://engineerscanada.ca/sites/default/files/Accreditation-CriteriaProcedures-2016-final.pdf

[4] Joel Hilchey, “Teaching against entitlementality.” In Proc CEEA Canadian Engineering Education Association Conf., CEEA13, (Montreal QC, June 17-20, 2013), 3pp. 2013. DOI: http://dx.doi.org/10.24908/pceea.v0i0.4847

[5] Justin Kruger and David Dunning, "Unskilled and unaware of it: How difficulties in recognizing one's own incompetence lead to inflated self-assessments.” Journal of Personality and Social Psychology, vol. 77, no. 6, pp. 11211134, 1999 DOI:http://dx.doi.org/10.1037/0022-3514.77.6.1121

[6] Natasha A. Mamaril, Ellen L. Usher, Caihong R. Li, D.Ross Economy, and Marion S. Kennedy, M.S. "Measuring undergraduate students' engineering self-efficacy: a validation study.” Journal of Engineering Education, vol. 105, no. 2, pp. 366-395, 2016. DOI: http://dx.doi.org/ 10.1002/jee:20121

[7] Homero Gregorio Murzi, H.G. "Team-based learning theory applied to engineering education: a systematic review of literature." In Proc. 121 ${ }^{\text {st }}$ ASEE Conference \& Exposition. (Indianapolis, IN, June 15-18), 2014. 12pp. Available as of May 15, 2017 from

https://www.asee.org/public/conferences/32/papers/10751/view 